\title{
IV. RESEÑAS
}

\section{Para ATravesar el goce}

Cristina Marqués Rodilla (2006): El Acontecimiento del Amor. De la insuficiencia del goce. Biblioteca Nueva: Madrid.

Amaya Ortiz de Zárate

\section{Solipsismo}

El ensayo de Cristina Marqués responde al propósito esforzado de construir un puente, de la mano de Allan Badiou, entre el sujeto y el goce - en el que se disuelve-trascendiendo los límites que la teoría lacaniana impone a la existencia misma del Sujeto. Si el sujeto lacaniano es producto de la técnica analítica, de la que derivaría la construcción del llamado "objeto a”, asexuado, Badiou apostará por un sujeto sexuado pero sin objeto, producto del acontecimiento amoroso.

\section{De la imposible relación sexual}

Es patente la impotencia del significante, en la teoría estructuralista de Lacan, para inscribir la diferencia sexual en el hablante. El Sujeto del inconsciente sólo podrá ponerse en relación con objetos parciales, de los que no obtendrá satisfacción; ya que el deseo dirigido al otro, a quien se sabe perdido para siempre, insiste sin embargo, indiferente al tiempo -la única ley. Será la pulsión articulada a cada nuevo significante, según dicta la fórmula del fantasma, lo que sustente el goce. Si la pulsión y el goce tienen su residencia en el cuerpo, el sujeto se aloja en el intervalo de la cadena sintagmática, por lo que su existencia misma constituye un vacío - sin nombre. 
Si bien el deseo originario del Sujeto se dirige a la alteridad del Otro, cuyo destino es caer para dejar en su lugar un objeto -objeto a-, no podrá el deseo sino caer en el bucle narcisista del otro -cualquier cosa-, para quien el sujeto no será en el extremo sino objeto - de un goce perverso.

Como puede leerse en Aún, recuerda Marqués, de existir el Otro sería precisamente el otro sexo, el Otro del significante. Pero no existe finalmente posibilidad alguna de conexión entre el lenguaje, entre el significante que constituye al Sujeto, y lo Real que es su alteridad. No existe relación simbólica porque no es posible vincular el goce y el lenguaje, o el lenguaje y lo Real.

A partir de 1964, en el seminario XI -Los cuatro conceptos fundamentales del psicoanálisis-, en lo que constituirá un movimiento progresivo, las fórmulas de la sexuación lacanianas, como constata fielmente Marqués, expresan la imposibilidad, el fracaso de la relación sexual.

\section{De la imposibilidad del Sujeto}

Con notable claridad y empeño en historizar señala Marqués que a partir de 1968 el Otro se vuelve, en la teoría lacaniana del Sujeto, inconsistente. Mediante la operación de situar el objeto a en el campo del Otro, se postula un Otro vacío, que no goza. El concepto mismo de objeto a no es sino el resultado del vacío abierto en el campo del Otro. Consecuentemente, ya no es un Sujeto el que habla, no hay propiamente sujeto de la enunciación. El Sujeto es hablado en un juego metonímico en el que jamás recibirá respuesta del Otro a su demanda, a su pregunta por el ser. En su lugar, el objeto a irá cobrando cada vez mayor protagonismo como su única consistencia, lo que sostiene y conforma a la vez al sujeto del inconsciente, que queda apresado en la fórmula del fantasma, condición suficiente y necesaria para definir la identidad del Sujeto y su deseo.

Hasta 1967, en la certera lectura de la autora, Lacan había sostenido la diferencia entre el Ser y el Sentido, entendido este último como significado -puro efecto 
de estructura. Pero aún era posible diferenciar el sujeto de la enunciación del sujeto del enunciado. A partir de ese momento, Lacan sostendrá más bien el anonadamiento, la imposibilidad del Ser para sostener una enunciación unitaria. El ser es únicamente el producto de la negación del yo -je. El sujeto ya no es fundado por la enunciación del Otro, su única verdad consiste en una alienación originaria en los significantes del Otro.

Queda así el Sujeto reducido a una pura intermitencia -entre el ser y el pensar. En la última producción de Lacan, el sujeto es una banda de Moëbius, una estructura cerrada sobre sí misma en una torsión que encierra en su centro un vacío -cuyo lugar será obturado por el objeto a.

\section{De la caída del Otro o la imposible Verdad}

La única identidad que Lacan sostiene a partir de 1966 es la de la pulsión y su goce, entendido éste como repetición. A esta única consistencia -plus de goce u objeto a- vendrá a denominar Lacan sustancia de goce o ser de goce. Es lo que hace al sujeto asexuado, en un juego entre el objeto y el sujeto, del que resulta la negación de toda diferencia, en tanto lo que puede proporcionar el objeto es un goce real, y no existe diferencia en lo real.

Podríamos decir también que a partir de este movimiento la simbolización de la escena primaria se ha vuelto imposible, y lo que queda es el fantasma imaginario, una escena fantasmática que proporciona un goce, un sufrimiento real, que es el destino del sujeto. Tampoco es posible ya ningún goce sublime, o un goce propio de la sublimación, porque no hay goce posible en la verdad (del significante). La única verdad a la que arriba el análisis, para el último Lacan, será la de la castración, la inconsistencia del otro, y la imposibilidad de la relación sexual. Para soportarlo, el sujeto deberá construir un fantasma que vele la falta y teja su discurso.

El único efecto de la interpretación será construir un punto exterior a la estructura del sujeto, el objeto a, en el mismo movimiento de corte en el que cae el Otro. 
El objeto a -objeto de goce- viene a sustituir al Otro, que si fue un tiempo significante simbólico para Lacan, se revela finalmente imaginario.

\section{La tarea del Sujeto en Badiou}

La propuesta de Badiou, que Marqués opone -como desarrollo- a Lacan, consiste en atravesar el punto muerto de la filosofía del ser, la antifilosofía de Lacan.

En su filosofía neoplatónica, el Sujeto insiste en su tarea de nombrar la verdad, una tarea heroica sin garantías de éxito; sin otra condición que la existencia de una experiencia amorosa real, y la asunción de la tarea de nombrarla y soportar esa verdad por parte de un sujeto. Un Sujeto producto de la escena simbólica: mítica, ontológica mitológica?-, capaz de convertir el carácter subjetivo de una experiencia azarosa en pura intersubjetividad.

\section{La diferencia sexual}

Si el amor para Lacan es un semblante para velar la falta - un vacío existencialpara Badiou el amor es el primer nombre de la verdad.

El acontecimiento amoroso, constituido en escena simbólica, funda la diferencia sexual y rompe al tiempo con el solipsismo inaugural del sujeto. Porque aquello que singulariza al sujeto no es sino su relación al otro: masculino o femenino.

\section{EI Ser abierto al infinito}

El Sujeto para Badiou será necesariamente sexuado, y sin embargo, sin objeto. Utilizando como modelo matemático el número transfinito de Cantor, el ser es vacío, es el cero originario, pero abierto al infinito. Un infinito actual que limita la serie de los números, como no-sucesor y cierre de la serie. El transfinito es el Otro, su contrapartida es el ser: el cero o el vacío. 
Reseña: "Para atravesar el goce”

El Sujeto se define en relación al Ser, no en relación a un supuesto goce perdido, sino a ese vacío radical de lo innombrable, que inscribe lo genérico. Badiou no habla de Sujeto del inconsciente, sino de sujeto militante del acontecimiento; su intervención, su acto de nominación, resulta imprescindible.

\section{La escena amorosa}

Hay dos posiciones de experiencia en la escena, hombre o mujer; la escena se experimenta pero es inefable o indecible. Sin embargo la palabra, el saber sobre la escena, hará surgir el amor. La escena es universal. La verdad es genérica. El enamorado mismo también lo es, porque el amor trasciende lo individual y promueve la verdad colectiva.

Son posibles únicamente dos lugares en la escena, masculino o femenino, no hay terceras posiciones. Se trata de lugares estructurales, verdugo o víctima. La regla para que se dé la conjunción, de inicio, exige que tanto el amor como el goce sean verdaderos.

La mujer aporta el lazo que permite al sujeto salir del solipsismo y encontrar su lugar en el Otro. Ella es el operador humanidad, porque elige sostener esa función que reúne y dota de sentido a los cuatro procedimientos genéricos -poesía, matemáticas, política y amor. De ella depende, entonces, tanto la subjetivación como la universalización de las verdades.

El goce femenino es infinito actual, y depende de la libre decisión de la mujer. El reposo en cambio, la nominación, es masculina y activa. La operación femenina consiste en aportar el sentido. Es de notar que sentido no equivale aquí a significado. La posición femenina dota de subjetividad al significado - estructural-, abriéndolo a la infinitud de la experiencia.

\section{El acontecimiento}


El acontecimiento entre el ser y el Otro precisará, para constituirse en escena, de la intervención de un Sujeto que lo nombre. Pues aunque el acontecimiento del amor se haya producido, sin declaración amorosa no habrá escena.

La verdad del sujeto depende de su fidelidad a un suceso genérico -imposible de apresar en un predicado-, que no está construido con anterioridad, pero que habrá sucedido -en un futuro anterior. Posee por ello un carácter infinito -es una Verdad con mayúscula- y aparece sólo retroactivamente, por la fidelidad del sujeto a la Verdad del acontecimiento que nombra y sostiene.

\section{Más allá de la repetición}

El forzamiento que la acción del sujeto realiza introduce la novedad, haciéndola existir y atravesando la repetición -la fuerza pulsional del goce. El azar es el lugar de lo real para Badiou, y se encuentra ligado al acontecimiento. El Sujeto realiza un forzamiento hacia la finitud del discurso y lo vuelve nombrable y repetible, en el sentido de posible. El significante y lo Real se unen por el acto de nominación del Sujeto y la fidelidad al propio acontecimiento. Como resultado, el significante adquiere una significación nueva y verdadera.

El corte es realizado aquí no por el analista, sino por el operador lógico que hace posible la cuenta -por uno- y reduce la multiplicidad, construyendo un subconjunto que se pertenece, dejando al Sujeto fuera. Esta Verdad es universal, va más allá del Sujeto, y no está circunscrita a ningún objeto parcial, o concreto, como el objeto a de Lacan.

La alienación en el deseo del Otro pierde así su fuerza por obra del suplemento de ser o ultraser que aporta la Verdad del acontecimiento. El objeto para el Sujeto, de tener alguno, sería por ello la Verdad por la que milita con coraje, porque le trasciende y su ser depende de ella. 
Reseña: "Para atravesar el goce”

\section{Para un posible Sujeto}

Cristina Marqués se pregunta por último si será legítimo resucitar el mito platónico del ser, y defender la existencia del Sujeto en un campo filosófico que ha acabado con toda ontología. La respuesta queda abierta: dependerá de la decisión de cada Sujeto que el acontecimiento del amor exista. 